\section{Commentary: Does the STABILISE technique stabilize the aneurysm in chronic dissection?}

\author{
Bo Yang, MD, $\mathrm{PhD},{ }^{\mathrm{a}}$ and David M. Williams, $\mathrm{MD}^{\mathrm{b}}$
}

Thoracic or thoracoabdominal aortic aneurysm (TAA/A) after acute aortic dissection is common. The standard treatment is open TAA/A repair. However, due to morbidities of the open repair, many surgeons and interventionists seek more minimally invasive approaches to treat this disease. The Achilles heel of endovascular treatment for TAA/A from chronic aortic dissection is the distal landing zone. Many creative techniques have been developed, such as wire septectomy, laser fenestration septectomy, open septectomy when repairing proximal aortic pathology through sternotomy, ${ }^{1}$ or just stent the true lumen of distal descending thoracic aorta to achieve thrombosis of the false lumen. ${ }^{2}$

Faure and colleagues ${ }^{3}$ borrowed the idea of Stent-assisted Balloon-induced Intimal Disruption and Relamination of Aortic Dissection (STABILISE) to treat acute and subacute aortic dissection and applied this technique in 17 patients with chronic dissection. Median follow-up time was 17 months. In this highly selected, small cohort of patients, the short-term outcomes were quite good. They had no operative mortality, 1 patient had type 1a endoleak requiring total arch replacement, and another patient had common iliac artery in-stent stenosis requiring angioplasty. They conclude that the STABILISE technique for treating TAA/A from chronic dissection was safe and effective.

Is the STABILISE technique safe in chronic aortic dissection? Every surgeon would worry about rupturing the aorta during ballooning to rupture the dissection septum. It would be relatively safe to balloon inside a stent graft with the bare-stent overlapping. However, is it safe to balloon the

From the Departments of ${ }^{\mathrm{a}}$ Cardiac Surgery and ${ }^{\mathrm{b}}$ Radiology, Michigan Medicine, Ann Arbor, Mich.

Disclosure: Authors have nothing to disclose with regard to commercial support.

Received for publication Feb 23, 2020; accepted for publication Feb 24, 2020; available ahead of print March 12, 2020.

Address for reprints: Bo Yang, MD, PhD, Department of Cardiac Surgery, Michigan Medicine, 5155 Frankel Cardiovascular Center, 1500 E Medical Center Dr, Ann Arbor, MI 48109 (E-mail: boya@med.umich.edu).

J Thorac Cardiovasc Surg 2021;162:1476-7

$0022-5223 / \$ 36.00$

Copyright (c) 2020 by The American Association for Thoracic Surgery

https://doi.org/10.1016/j.jtcvs.2020.02.114

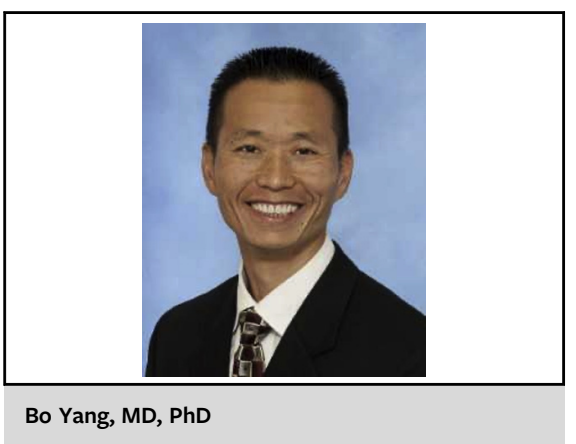

CENTRAL MESSAGE

It was an interesting idea, but the study was too small $(\mathrm{N}=17)$ and follow-up was too short (median, 17 months) to make a definitive conclusion.

bare stent distal to the stent graft all the way to the infrarenal aorta? It is still questionable. In the 17 patients, the authors report no aortic rupture. How about 170 cases or 1700 cases?

In chronic aortic dissection, the true lumen is much smaller than the whole aorta, as illustrated on computed tomography scans and confirmed during open repair. When the septum is ruptured, the separated edges can be compressed by a stent against the aortic wall, but they can no longer be stretched to cover the entire outer wall of the false lumen. The concept that bare stent stretches out the intimal flap to cover and buttress the outer wall of the false lumen, so-called relamination, is counterintuitive and is not supported empirically or by surgical finding during open repair of chronic aortic dissection. Because the intimal flap is too small to cover the entire wall of the false lumen, the uncovered outer wall of false lumen is not buttressed and remains exposed to the blood pressure. Indeed, rupturing the flap creates a large fenestration, which as shown by Berguer and colleagues ${ }^{4}$ in a bench-top model of dissection, can by itself depressurize the false lumen. In short, it may be that the fenestration (intimal disruption) rather than relamination is the crucial feature of this treatment. Furthermore, the median decrease in maximal aortic diameter in this study was $3 \mathrm{~mm}$ (range, $0-17 \mathrm{~mm}$ ) in 17 patients with median follow-up of 17 months, and it is too early to conclude that it is effective.

Besides aortic rupture, another concern is distal embolization from thrombus in the false lumen. Thrombus from false lumen could be dislodged by the expansible bare stents 
and embolize downstream to distal branch vessels, as happened in a patient in this study. It is very wise for the author to list the presence of false lumen partial thrombosis at the rupture point as a contraindication.

It is a very interesting concept to apply the STABILISE technique to treat thoracic aortic aneurysm from chronic dissection. However, larger sample sizes and longer follow-ups are needed to support the safety and effectiveness of this technique.

\section{References}

1. Roselli EE. Optimization of distal landing zone for TEVAR in chronic dissection. Ann Cardiothorac Surg. 2014;3:329-32.

2. Hughes GC, Ganapathi AM, Keenan JE. Thoracic endovascular aortic repair for chronic Debakey IIIb aortic dissection. Ann Thorac Surg. 2014;98:2092-8.

3. Faure EM, Batti SE, Sutter W, Bel A, Julia P, Achouh P, et al. Stent-assisted balloon dilatation of chronic aortic dissection. J Thorac Cardiovasc Surg. 2021; $162: 1467-73$

4. Berguer R, Parodi JC, Schlicht M, Khanafer K. Experimental and clinical evidence supporting septectomy in the primary treatment of acute type B thoracic aortic dissection. Ann Vasc Surg. 2015;29:167-73. 